\title{
Using the dynamic mapping of the microwave brain radiation for functional studies
}

\author{
Vladimir S. Kublanov, Vasilii I. Borisov, Anton Y. Dolganov \\ Research Medical and Biological Engineering Center \\ of High Technologies, Ural Federal University, Russia \\ v.s.kublanov@urfu.ru
}

Abstract. In this study, organizational principles of the radiophysical complex are proposed for simultaneous measurements of the brightness temperature fluctuations of the human brain and parameters of the autonomic nervous system. A new structure of the medical microwave radiothermograph is suggested based on the parametric compensation of losses in the circuit elements of the thermobalance. The aim of this article is to justify the structural organization of the radiophysical complex for the recording and joint real-time analysis of processes of the microwave radiation formation in the brain tissue and characteristics of the autonomic nervous system. Description of the radiophysical complex MRTHR with realization of these principles is presented. The peculiarity of the proposed radiophysical complex is in passive elements that do not contain electronic nodes and blocks and are inside the shielded cabin. In order to increase the accuracy of the brightness temperature of the deep brain structures measurement in the radiophysical complex a new structure is implemented. This structure of the medical microwave radiothermograph is based on the parametric compensation of losses in the circuit elements of the thermobalance.

Keywords. Microwave brain radiation, medical radiothermograph, radiophysical complex.

(C) Kublanov V. S., Borisov V. I., Dolganov A. Y., 2018

\section{Introduction}

Nowadays, mechanisms of the microwave radiation formation in the brain tissue have been studied insufficiently. U. V. Guliaev and E. E. Godik proposed the hypothesis that proper human physiological field is parametrically modulated by biochemical and biophysical processes of the organism [1] However, this theory defines only a general direction in the research of regularities of a phenomena and processes in the brain tissues.

Application of theories and methods of synergetic systems to solve this task is perspective, since complex systems (like neuron networks, neuroglia, meninges, cerebrospinal fluid system, and the blood supply system) all participate in organization of its functionality [2].

The system of blood supply in brain is a complex multi parameter non equilibrium self-organized, which has cross-links. This system is controlled by 
neurogenic, humoral, metabolic, and myogenic regulatory circuits. The vascular muscles are executive elements in the mechanism of blood supply regulation in the brain. They perceive the irritation from specialized receptors and chemical compounds that fall into the blood and environment. These muscles also perceive the mechanical stretching of the blood pressure in the vessels and are sensitive to a number of substances that are products of cellular metabolism [3].

One can note the role of the automatic nervous system (ANS) in these processes, since the irritation of specialized receptors is provided mostly by the sympathetic part of the ANS [4]. However, in some vascular reactions, the parasympathetic fibers take part. The mechanism of the formation of the brain microwave radiation is connected with the Brownian thermal motion of charge carriers.

The goal of this article is to justify the structural organization of a special radiophysical complex. The complex is used for the recording and dynamic mapping for real-time analysis of processes of the microwave radiation formation in the brain tissue and investigation of characteristics of the ANS.

\section{Materials and methods}

Traditionally, contact microwave radiometers are used in the registration of microwave radiation of biological objects; and it is essential to define frequency boundaries of the receiving channel.

If brain tissues are studied, on the one hand it is advisable to monitor processes in frequency bounds that allow one to receive radiation from the depth of 4-5 cm. On the other hand, the decrease of frequency leads to the decrease of the spatial resolution of the studied field. The computer simulation of this problem showed that frequency band ranging from 650 to $850 \mathrm{MHz}$ is optimal [5].

It is worthy to note, that studies in this band is possible only with the microwave screening of the object. Since this frequency band has a lot of industrial noise, in this case, necessary electric impermeability is defined by the particular electromagnetic environment. The experience of microwave radiometers application in medical institutions showed that interchanged level of 50-60 dB is enough.

Therefore, the radiophysical complex should include the electromagnetic cabin and microwave elements with all input and output conducting channels to be screened. The mobile variant is more preferred when screened cabin is done as a capsule. This capsule is placed on a mobile carrier (cart). As a result, the studies may be conducted without restrictions and as close as possible to a patient in clinical settings.

In fig. 1, the structural diagram of the radiophysical complex for the measurement and complex real-time analysis of processes of the microwave radiation formation in the brain tissues and characteristics of the ANS. 


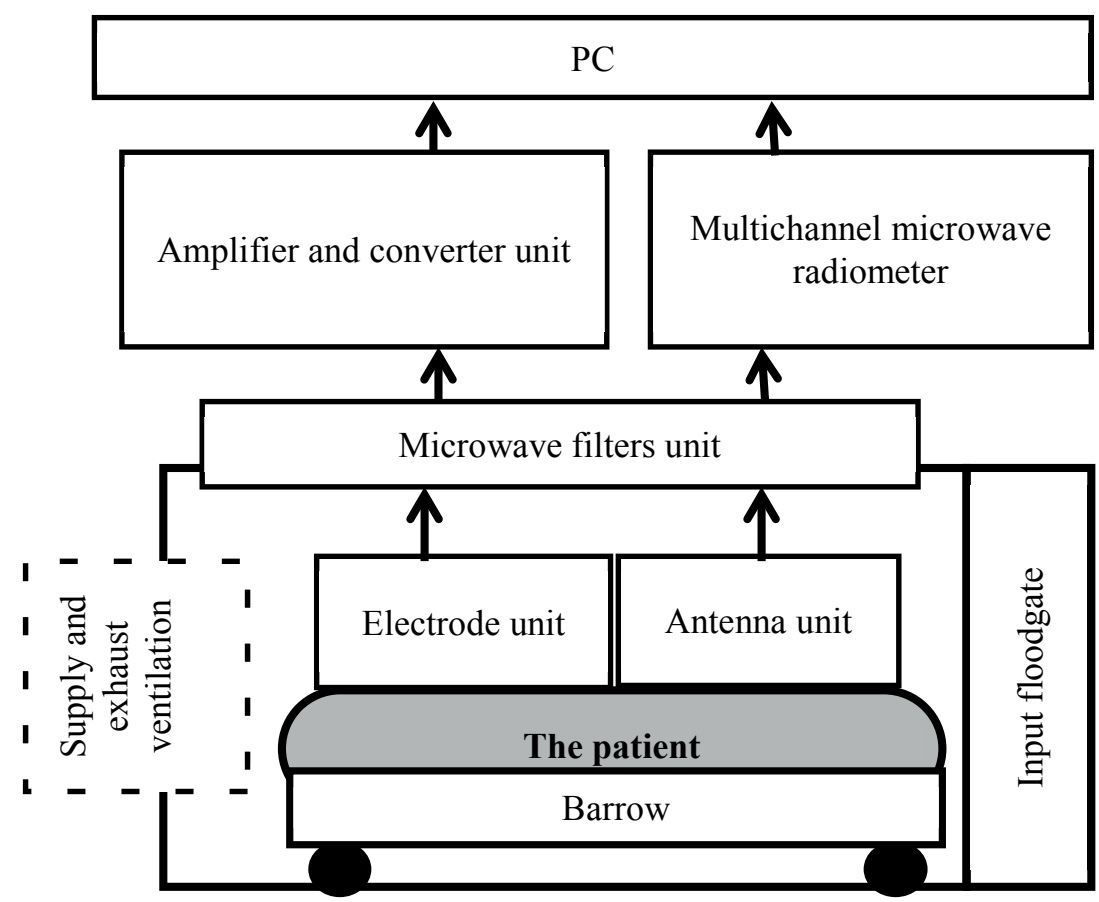

Fig. 1. Structural diagram of the MRTHR-40 radiophysical system forexamining functional state of a patient's brain

Characteristics of the signal that add noise may vary depending on the structure of the microwave radiometer and the algorithms of the thermobalance formation in the input part, which we call the schematic of the thermobalance.

We have investigated and constructed the technical solutions based on the following principles [3]:

1. The formation of two or more auto-regulation regimes implemented by the reconfiguration of the structural thermobalance schematic.

2. The formation of two or more auto-regulation regimes implemented by the control of losses in the circuit elements of the thermobalance.

3. The parametric compensation of losses in the circuit elements of the thermobalance.

In the first two items, a number of independent equations is formed. This number depends on the disturbance parameters. Solution of these equations gives estimations that allow one to compensate the brightness temperature fluctuations caused by the mentioned disturbance factors.

The common thing in various thermobalance schematic is that the antenna-body system 'noising' [6] is performed in certain cycles of radiometers with the specialized noise generator. This generator directs the signal to the antenna. After that, the signal is reflected from antenna to the receiver's input.

In fig. 2, the equivalent schematic of input modulation chains of the microwave radiometer is shown. 


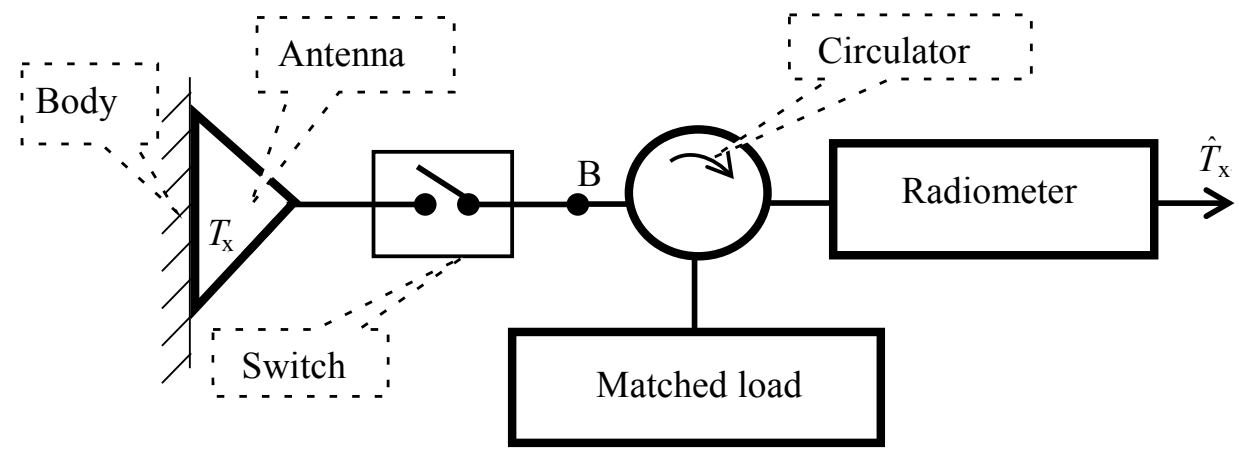

Fig. 2. The equivalent schematic of input modulation chains of the Ludekecircuit

The basis of the theory of contact radiometer measurements of biological tissues were developed by V. S. Troitskii [6]. Troitskii showed that the signal $T_{\mathrm{B}}$ at the point $\mathrm{B}$ of the radiometer Ludeke can be written as follows if there is no losses and reflections in schematic (fig. 2):

$$
T_{B}^{(1)}=T_{\mathrm{x}}\left(1-\Gamma_{0}^{2}\right) \eta_{\mathrm{A}}+T_{\mathrm{ML}} \Gamma_{0}^{2} \eta_{\mathrm{A}}+T_{\mathrm{A}}\left(1-\eta_{\mathrm{A}}\right) .
$$

In equations (1)-(4): $T_{\mathrm{x}}$ is the radio-brightness temperature of body, $T_{\mathrm{A}}$ is the thermodynamic temperature of antenna, $T_{\mathrm{ML}}$ is the noise temperature of the matched load, $\eta_{\mathrm{A}}$ is the antenna efficiency, $\Gamma_{0}^{2}$ is the ratio of antenna/body matching [7].

If the reflection ratio $\Gamma$ is equal to $\Gamma_{0}^{2}$ (that characterizes the antenna body matching) then it is possible to realize the independent condition in the thermobalance schematic of the measurement of the own microwave radiation $T_{\mathrm{x}}$ from $\Gamma_{0}^{2}$.

At the position of the modulator switch when the controlled noisegenerator (matched load) is connected to the input of the radiometer circulator, the signal $T_{B}^{(2)}$ at the point $\mathrm{B}$ is as follows:

$$
T_{\mathrm{B}}^{(2)}=T_{\mathrm{ML}} \text {. }
$$

If the signals are equal $\left[T_{\mathrm{B}}^{(1)}=T_{\mathrm{B}}^{(2)}\right]$, then according to the equations (1), (2):

$$
\widehat{T}_{\mathrm{x}}=\frac{T_{\mathrm{ML}}\left(1-\eta_{\mathrm{A}} \Gamma_{0}^{2}\right)-T_{\mathrm{A}}\left(1-\eta_{\mathrm{A}}\right)}{\eta_{\mathrm{A}}\left(1-\Gamma_{0}^{2}\right)} .
$$

The equation (3) shows that measured radio-brightness temperature $T_{\mathrm{x}}$ is transmitted to the input of the radiometer changed by an undefined value. This value depends on a priori unknown parameters of the antenna $\eta_{A}$ 
and $\Gamma_{0}^{2}$. Efficiency $\eta_{\mathrm{A}}$ of the antenna depends on the design and its technological implementation and is a relativity stable parameter [8]. On the other hand, the ratio $\Gamma_{0}^{2}$ may vary not only between different investigations, but, also, during the process of the measuring due to changes in the blood circulation in the study area, as well as, the influence of the "greenhouse" effect (the thermobalance disturbance).

If the antenna's and the body's temperatures at the contact area and temperatures of the circulator and input of the resistant are equal, then equation (3) may be rewritten as follows:

$$
T_{\mathrm{x}}=T_{\mathrm{A}}=T_{\mathrm{ML}} .
$$

In this way, we exclude uncertainty of measured radio-brightness temperature $\widehat{T}_{\mathrm{x}}$ transmission to the input of the radiometer on antennas parameters $\eta_{\mathrm{A}}$ and $\Gamma_{0}^{2}$.

It is worthy to mention that it is impossible to maintain constant temperature close to the temperature of the body in the circuit elements of the thermobalance and at inputs of the radiometer. It appears especially during functional studies of the brain. Moreover, one should not neglect losses and reflecting heterogeneities of the circuit elements of the thermobalance if they change during the process of functional study [9].

\section{Results and discussion}

The peculiarity of the proposed radiophysical complex is that only passive elements are inside the shielded cabin that do not contain electronic nodes and blocks. This structural scheme is implemented in the radiophysical complex MRTHR. In this complex, a modernized multichannel microwave radiothermograph is used with the parametric compensation of losses in the circuit elements of the thermobalance.

The structural schematic of this complex is presented in fig. 3 .

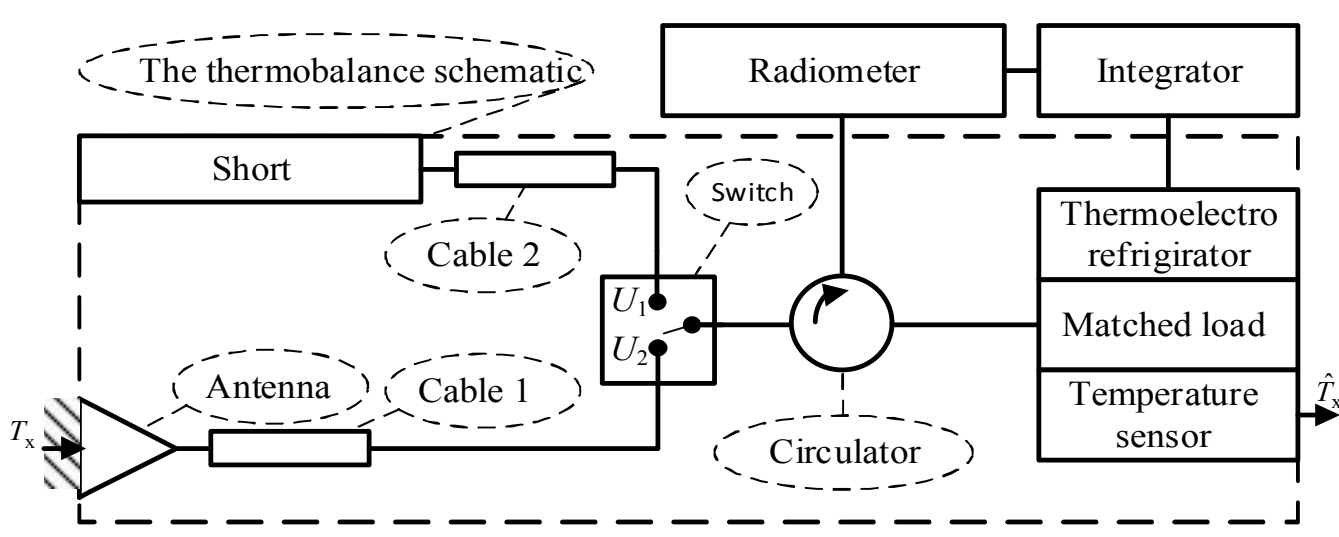

Fig. 3. Structural schematic of the microwave radiothermograph with parametric compensation of losses in the circuit elements of the thermobalance 
Therefore comes the equation of the transmission for two states of the thermobalance schematic of the proposed microwave thermograph. At the first state the switch provides the signal transmission from the antenna to the input of the radiometer. At the second state the switch provides the signal transmission from the short to the input of the radiometer.

There are some necessary notations: $U_{1}$ is the signal on the input of the radiometer in the first state, $U_{2}$ is the signal in the second state. The equation of the autoregulation of the thermobalance schematic for the microwave radiothermograph MRT-40 we write down as follows:

$$
\left\{\begin{array}{c}
\mathrm{T}_{C H}\left(1-\gamma_{\amalg}\right)\left(1-\gamma_{\mathrm{K} 2}\right)\left(1-\gamma_{\mathrm{K} 3}\right)^{2}+\mathrm{T}_{\mathrm{K} 2} \gamma_{\mathrm{K} 2}+\mathrm{T}_{\mathrm{K} 3} \gamma_{\mathrm{K} 3}\left(1-\gamma_{\mathrm{K} 2}\right)=U_{1} \\
\mathrm{~T}_{g}\left(1-\Gamma_{\mathrm{c}}^{2}\right)\left(1-\gamma_{\mathrm{A}}\right)\left(1-\gamma_{\mathrm{K} 1}\right)+\mathrm{T}_{C H}\left(1-\gamma_{ц}\right)\left(1-\gamma_{\mathrm{K} 1}\right)\left(1-\gamma_{\mathrm{A}}\right)^{2} \Gamma_{\mathrm{c}}^{2}+ \\
+\mathrm{T}_{\mathrm{A}} \gamma_{\mathrm{A}}\left(1-\gamma_{\mathrm{K} 1}\right)+\mathrm{T}_{\mathrm{K} 1} \gamma_{\mathrm{K} 1}=U_{2} \\
U_{1}=U_{1}
\end{array}\right.
$$

where $\gamma_{\mathrm{c} 1}, \gamma_{\mathrm{c} 1} \gamma_{\mathrm{s}}, \gamma_{\mathrm{c} 2} \gamma_{\mathrm{s}}, \gamma_{\mathrm{A}} \gamma_{\mathrm{sh}}, \gamma_{\mathrm{A}}, \gamma_{\mathrm{c}}$ are the loss ratios of the first and second cables, short, antenna and circulator respectively. $T_{\mathrm{c} 1}, T_{\mathrm{c} 2}, T_{\mathrm{A}}, T_{\mathrm{s}}, T_{\mathrm{x}}, T_{\mathrm{ML}}$ are the "noisy" temperatures of the first and second cables, the antenna, the short, the radio-brightness temperature of the body and the temperature of the matched load accordingly; $\Gamma_{0}^{2}$ is the reflection ratio of the "antenna-body" border.

When processes are regulated $\left(T_{\mathrm{c} 1}=T_{\mathrm{c} 2}=T_{\mathrm{A}}=T_{\mathrm{s}}, \gamma_{\mathrm{c} 1}=\gamma_{\mathrm{c} 2}\right)$ and losses in the antenna and the short are insignificant two states are equal. Therefore the autoregulation equation can be rewritten as follows:

$$
\widehat{T}_{\mathrm{x}}=T_{\mathrm{ML}}\left(1-\gamma_{\mathrm{c}}\right) .
$$

So, the measurement of the proper microwave radiation of the brain is the radiobrigtness temperature of matched load, which is proportional to its thermodynamic temperature. Changes of the temperature scale defined by multiplier $\left(1-\gamma_{c}\right)$ can be determined during calibration of the radiothermograph.

\section{Conclusion}

The described structural organization was tested during the development of the radiophysical MRTHR complex [10].

Despite of the fact that the role of the ANS in the regulation of the cerebral blood circulation is obvious, many mechanisms of this regulation remain unclear. In existing literature, these issues are described incompletely, even though the knowledge about the role of the ANS in the formation of functional processes in the brain tissue allows answering many questions about their pathogenesis.

In our previous papers, the spectral and correlation methods were used for data processing and analysis [2,3]. However, the given complexity of the 
dynamic control systems that form the considered biomedical results would not necessarily be an objective assessment of these signals. So, the analysis of statistical self-similarity of time series is promising, whether the characteristics of time series comply with the requirements of the multifractal formalism [4].

For implementation of the processing unit and data analysis of non-stationary time series of biomedical signals, the multifractal fluctuation analysis method was applied; its detailed description will be presented in further works.

The designed radiophysical MRTHR complex has been clinically tested in the Sverdlovsk regional clinical psycho-neurological Hospital for War Veterans (Yekaterinburg, Russian Federation). The tests have shown that the MRTHR can be used to obtain new knowledge about the dynamic mapping of the functional processes of the brain [3].

\section{References}

1. Godik E. E., Gulyaev Y. V. Functional imaging of human body. IEEE Engineering in Medicine and Biology, 1991, 10 (4), pp. 21-29.

2. Kublanov V. S., Sedelnikov Ju. E., Azin A. L., Syskov A. M. The Nature of Fluctuations Own Electromagnetic Radiation of the Brain. Biomedical Radioelectronics, 2010, 9. pp. 45-54.

3. Kublanov V.S. Radiophysical system for examining functional state of a patient's brain. Biomedical Engineering, 43 (3), 2009, pp. 114-119.

4. Kublanov V. S., Borisov V.I, Porshnev S. V. Features of using nonlinear dynamics methods for heart rate variability analysis. Biomedical Radioelectronics, 2014, 8, pp. 30-37.

5. Kublanov V. S., Dorofeev V.A., Kostousov V. B. Mobile radio-physical system for the functional researches of brain. Proc. of the $4^{\text {th }}$ Russian-Bavarian Conference on Biomedical Engineering. 2008, Moscow, pp. 253-257.

6. Troitskii V.S. On the theory of contact radiometric measurements the internal temperature of bodies.Izv. VUZ., Radiofiz., 1981, 24 (9), pp. 1054-1061.

7. Klemetsen O., Birkelund Y., Jacobsen S. K. Design of medical radiometer front-end for improved performance. Progress in electromagnetics research B, 2011, 27, pp. 289-306.

8. Ludeke K. M., Koehler J., Kanzenbach J. A new radiation balance microwave thermograph for simultaneous and independent temperature and emissivity measurements. Journal Microwave Power, 1979, 14, pp. 117-121.

9. Vaisblat A. V. Medical RTM-01-RES. Biomedical technology and electronics, 2001, 8, pp 3-9.

10. Kublanov V. S., Dorofeev V.A., Sirotin A. I., et al. Patent No. 2073875 (RU), MPK7 G01R 29/08, G01S 13/95, Zero radiometer. Bulletin of inventions, 1997, 5. 
Информация об авторах

Кубланов Владимир Семенович - д-р техн. наук, профессор, руководитель Научно-исследовательского медико-биологического инженерного центра высоких технологий ИРИТ-РтФ; e-mail: v. s.kublanov@urfu.ru.

Борисов Василий Ильич - канд. техн. наук, старший преподаватель; e-mail: v. i.borisov@urfu.ru.

Долганов Антон Юрьевич - аспирант, младший научный сотрудник; e-mail: anton.dolganov@urfu.ru.

\section{Information about the author}

Vladimir S. Kublanov is a Professor, Director of Research Medical and Biological Engineering Center of High Technologies of Radioelectronics and Information Technologies Institute. (Ekaterinburg, Russia); e-mail: v. s.kublanov@urfu.ru.

Vasilii I. Borisov is a Candidate of Engineering Sciences, Associate Professor at Ural Federal University named after the first President of Russia B. N. Yeltsin (Ekaterinburg, Russia); e-mail: v. i.borisov@urfu.ru.

Anton Y. Dolganov is a postgraduate, research scientist of Research Medical and Biological Engineering Center of High Technologies of Radioelectronics and Information Technologies Institute. (Ekaterinburg, Russia); e-mail: anton.dolganov@urfu.ru. 